\title{
Student Attitudes to MIS Content in an MBA: A Comparison across Countries
}

\author{
Stephen Burgess \\ Victoria University, \\ Australia \\ Stephen.Burgess@vu.edu.au
}

\author{
Golam M Chowdhury \\ Victoria University \\ International, Bangladesh \\ gmc@accesstel.net
}

\author{
Arthur Tatnall \\ Victoria University, \\ Australia
}

Arthur.Tatnall@vu.edu.au

\begin{abstract}
Export education forms a major part of the Australian economy. Australian universities are now not only accepting overseas students into Australian campuses; they are setting up overseas-based campuses. This is often through an arrangement with a local educational institution or organisation. Subjects in these institutions are delivered by a combination of Victoria University Australian-based staff and local faculty. One of the primary programs being delivered overseas by many Australian institutions is the Master of Business Administration (MBA). This paper examines the delivery of the core information technology units, Management Information Systems (MIS), by Victoria University in Australia and overseas (in Bangladesh). The structure of the MBA at Victoria University in Australia and overseas is examined and the MIS subject explained. Results of a survey of MBA students' views of the content of MIS, conducted in Australia (1997-2000) and Bangladesh (2001) are reported. There is little difference in the attitudes of students of both countries in relation to the topics covered in the subject, nor on the breakdown of the subject between 'hands-on' applications and more formal instruction. There are some differences in relation to the level of Internet and e-mail usage, with Australian students tending to use these technologies on a greater basis as a proportion of their overall computer usage.
\end{abstract}

Keywords: Computers, information technology, management information systems, MBA programs, management education, developing countries

\section{Introduction}

Export education is a major part of Australia's economy, whether it is conducted in Australia or overseas. This paper examines the viewpoint of MBA students to content in the Management Information Systems (MIS) core subject, particularly in Australia and Bangladesh. Viewpoints of students studying the MIS subject at both campuses are compared with a view to seeing if there are any differences in attitudes towards the content.

\section{International Education by Australian Universities}

Material published as part of these proceedings, either on-line or in print, is copyrighted by Informing Science. Permission to make digital or paper copy of part or all of these works for personal or classroom use is granted without fee provided that the copies are not made or distributed for profit or commercial advantage AND that copies 1) bear this notice in full and 2) give the full citation on the first page. It is permissible to abstract these works so long as credit is given. To copy in all other cases or to republish or to post on a server or to redistribute to lists requires specific permission from the publisher at Publisher@intormingscience.org
The education industry in Australia is an important component of its economy. It represents the country's eighth largest export industry (worth $\$ 3.7$ billion per year) and is only second to tourism as a services export earner. Asian students in particular are attracted to Australia because of its friendly environment, the quality of education and the chance to receive a qualification in English, all at a lower cost than in the USA or the UK (Cameron, 2001). In addition to this, Australian universities are now 
expanding their offerings, mostly in Asia, by setting up overseas-based campuses offering a limited number of their educational programs. For instance, Victoria University currently has campuses set up (or in shared campus arrangements) in Bangladesh, China, Hong Kong, Malaysia and Singapore, with negotiations currently underway with other countries in the region. Subjects at overseas campuses are normally delivered in 'condensed mode' of one week of lectures by Victoria University's Australian-based staff, supported by a series of workshops over a number of weeks by locally-based staff. In this market, Victoria University finds itself competing with local universities, other Australian-based universities, other overseas-based universities (such as those from the West Coast of the US) and other new initiatives, such as Internet-based courses.

\section{MIS in the Generic MBA Program}

The content of information technology (IT) subjects differs markedly across various MBA programs. Some of the reasons for this variation are the number of contact hours, the sequencing of the subject in the course, and content decisions made by course designers (Silver, Markus et al. 1995). Due to the broad range of topics covered in these courses it is unlikely that any of the topics will be covered to any significant depth (Burgess and Tatnall 1997; Tatnall, Davey et al. 2000).

'A Guide to MBA Programs' has been published in Australia for a number of years now (see Dwyer and Marshall 1993; Clout and Marshall 1995), and shows the institutions offering MBA courses in a particular year. Details of the subject offerings of many of these courses are also offered. Subjects containing a substantial IT component can be readily identified by their title. For instance, subject titles such as Management Information Systems, Information Systems and Computing and Information Systems could be safely identified as having a substantial IT component. It is reasonable to suggest that other subject titles, such as Information Management, also have a substantial IT component.

There has been little change in the IT component of generic MBAs over the seven year period 1993-2000. Over $60 \%$ of all generic MBA courses contain a compulsory IT subject. The majority of the others provide an IT elective, indicating that the majority of institutions offering generic MBAs acknowledge the importance of providing at least basic IT knowledge to the MBA graduate.

General personal computer (PC) skills appear to be taught adequately in most MBAs, either indirectly or as part of the dedicated curriculum (Burgess and Tatnall 1997). PC literacy does not, by itself however, provide an adequate understanding of how IT can be effectively used in business. In many cases, graduating students will not be using the technology, but will need to understand how it could be appropriately deployed to solve a business problem (La Plante 1991). Students should be equipped to understand how to maximise the benefits, avoid the dangers and be aware of the limitations of IT (Silver, Markus et al. 1995).

Sauer et al. (1996b) classified the content of core MBA IT subjects into four main types. These focus on a combination of:

- Computing skills - use of word processing, spreadsheets and database management packages with some study of computing fundamentals.

- Introduction to MIS - systems fundamentals; development, planning, management and applications of information systems; organisational change

- Managing IT - general management issues, business strategy, organisational change, implementing IT, management of the IT function.

- Special topics - including operations management, auditing, special applications, decision support systems, etc.

Of the core IT subjects offered in the universities that were sampled, $67 \%$ focused on 'Introduction to MIS' and $20 \%$ on 'Basic computing skills', with only small numbers relating to the other course types. 
Taken together with the percentage of courses containing a core MIS subject, this means that only about $50 \%$ of all general MBA programs in Australia have a core unit of either the 'Introduction to MIS', or 'Managing IT' type (Sauer, Sharma et al. 1996a), meaning that half of the students undertaking general MBA programs can graduate without any formal introduction to the development or management of information systems.

Tatnall and Davey (2000) argue for the inclusion of a subject of the 'Introduction to MIS' type as a core subject in any generic MBA. They argue that the subject should include a substantial amount of work on systems development, not because they think that these students will need to build their own information systems, but because they believe that only by an involvement with this can students gain an understanding of the difficulties and issues involved.

\section{The MBA at Victoria University}

The Faculty of Business at Victoria University of Technology (VU) began offering Master of Business Administration (MBA) programs in 1992. In addition to local students, in recent years the MBA program has also become increasingly popular with overseas students: those enrolled in Melbourne and those enrolled overseas. The course format is that of a generic MBA with a total of twelve subjects taken over three semesters. The MBA program is currently (2002) offered off-shore in Singapore, Beijing (China) and Dhaka (Bangladesh). This paper compares the perceptions of MIS students in Melbourne over a period of years with those that were taught in Dhaka for the first time in 2001.

Australian business schools offer a range of diverse MBA courses. These are a blend of the American MBA - with a technical approach to management, and the European MBA - with emphasis placed on a more practical approach (Dwyer and Marshall 1993). This paper discusses generic MBA programs, rather than specialist programs or programs directly sponsored by corporations.

From the outset, the MBA at Victoria University has included the core subject of Management Information Systems (MIS). This subject is offered in first and second semester in Melbourne (with typically about 60 students each semester) and usually also in summer semester (December - February) with a group of around 20 students. The overseas delivery of the subject is usually every third or fourth semester, with most overseas campuses running three semesters a year (trimesters?) to groups of 20-50 students.

\section{The MBA Program in Bangladesh}

The program in Bangladesh is conducted under the joint initiative of Victoria University International (VUI) and BETS Victoria Ltd (BVL), which is a sister concern of Bangladesh Engineering and Technological Services (BETS). The later is a major player in the engineering consultancy services, mainly operating in Water Resources Management, Health, IT and other development sectors. Although BETS did not have the experience of running an academic institution, it had a good corporate image and the financial strength to host VUI MBA program in purpose-built state of the art facilities in the heart of Dhaka (the capital city).

The program was launched in February 2001 and the first cohort of MBAs started in April. In its third intake it has a student body of over seventy. The students come from diverse backgrounds including multinational manufacturing and trading, local and foreign financial institutions, the armed forces, NGOs and international bodies. The student body consists of less than $10 \%$ female population, which is not abnormal for a program aimed at only students with work experience and conducted during evenings and weekends. Most students are self financed (own and family supported), however there has been a number of corporate sponsorships, and this is on the increase. The program already has participation from foreign countries such as China, Malaysia and the Philippines, although few in number at present. 
Considering that private sector university education is a relatively recent phenomenon (introduced under the private university act 1992), the response to VUI program is quite encouraging. Since the legislation there are about seventeen private sector universities offering MBA programs in the country. Some of these universities are also having foreign collaborations (credit transfer, faculty and student exchange, and so forth) with North American, European and Australian academic institutions. In parallel to this there are five off-campus operations like that of the VUI MBA program.

\section{MIS in the MBA at Victoria University}

The subject BCO 6503 Management Information Systems has been taught in the MBA at Victoria University since the course was introduced. In that time the lecturers involved in the subject (including two of the authors of this paper) have had three major goals:

- To provide students with a management-level understanding of the contribution (strategic or otherwise) that Information Technology can make to business.

- To provide students with a basic understanding of the information systems development process and the roles of IT personnel (such as systems analysts, designers and programmers) in this process, so that they may better interact with these personnel in a management context.

- To provide students with some introductory level PC literacy skills so that they may complete their course and feel comfortable using a PC after its completion.

In common with most similar courses, the MBA at Victoria University has no prerequisite for previous studies in computing. As a matter of interest, those students with a strong background in IT are generally discouraged from studying the subject in Melbourne. This is not always possible overseas, where a limited number of subjects are often offered. The MIS subject attempts to take management students from a starting point where no previous computing knowledge is assumed, and introduce them to a wide range of concepts and issues in information technology. Each topic is approached from the standpoint that as future managers these students are unlikely to be building computer systems, but that an understanding of the concepts involved will make them better able to work with, and to manager, those who do.

By the time they have completed the subject the students have learned something of the various types of information systems used in organisations, issues of systems integration, project management, networks and data communications, the management of technological change, electronic commerce, how information systems are used for strategic advantage and how these systems are built. In discussing the building of information systems, students are introduced to concepts of process modelling, data modelling and IT project management. In the computing laboratory students use Microsoft Excel, Access and Project to reinforce theoretical concepts discussed in seminars. It is made clear to students that concept development is the goal rather than to teach the full use of these packages.

The teaching approach adopted by the authors has been to integrate systems development concepts with management issues, and theoretical lecture material with practical discussion and laboratory work. This has been done for pedagogic reasons as both authors believe that students, even at the postgraduate level, understand better by doing than by just listening.

\section{Challenges Delivering MIS in Melbourne and Overseas}

One of the immediate challenges facing staff delivering any subject overseas is the difference in delivery modes. In Australia, subjects are typically taught over 13 weeks in a three-hour combination of lectures, workshops and seminars. When delivered overseas, Australian-based staff are usually based at the local campus for around one week, normally delivering 15 hours of lectures. This is followed by a number of workshops delivered by local staff (usually a series of 3 hour workshops delivered over eight or nine weeks). It is difficult for Australian-based staff to keep much control over the conduct of the subject, but 
this has improved over recent years with better access, and a greater reliance on e-mail. Still, some situations cannot be handled as easily overseas as they can in Australia. A recent example occurred in the MIS workshops in Bangladesh, where the workshop leader was stricken by Dengue fever and was absent for two weeks. In Australia, this (unlikely) situation could be 'covered' in the short term by another member of staff. In Bangladesh, it was necessary to reschedule classes, forcing scheduling problems with the need to conduct examinations and view student presentations before the next Australian staff member arrived to conduct classes for the next subject.

There are also challenges for teaching business-based information technology subjects overseas. It is important to match the content of the subject with the local environment, whilst keeping the standard of assessment as similar as possible to that expected of students in Melbourne. Not all countries (particularly Bangladesh) have the same level of technological infrastructure as Australia. The level of development of IT in countries such as Bangladesh is influenced by factors such as the infrastructure available and actually deployed, levels of regulation and, of course, the economic situation (De Boar and Walbeek, 1999). In Bangladesh, only 3\% of homes have a telephone. As such, entrepreneurs are able to purchase mobile phones through loans with the local Grameen bank and service the loans by charging other villagers to make calls. It can also work out cheaper for the villagers, allowing them to save money by avoiding long and expensive trips (typically three to ten percent of monthly household income). In many poorer countries, the number of mobile phone users exceeds the number of regular telephone users. The proportion of Internet users in developing countries is also increasing. In 1998, 12\% of Internet users were in less developed countries. By 2000 this had risen to $21 \%$ at a time when the number of Internet users worldwide had doubled (The Economist, 2001). The cost of purchasing a computer in Bangladesh is prohibitive for the general population, costing the equivalent of eight years' average pay. However, one of the advantages of being that far behind in relation to information technology is by knowing already what technology is best suited to particular tasks and not having to learn the lessons of development when the technology was introduced for the first time. It is likely that computers, communications technologies and the Internet will diffuse at a rapid rate (compared to other technologies) as it is in their nature to lower communication costs and break down international barriers (The Economist, 2000). As it is, the typical student studying an MBA with Victoria University at Dhaka works full-time, and many of them have access to computers (and some, the Internet) at work. Of course, access to the technology is one thing. Knowing how to use it effectively is another (Persuad, 2001). This is hopefully an area where the MIS subject can make an impact.

\section{The Study: Australia and Bangladesh}

Questionnaires were distributed to students of MIS in Melbourne in the final class of the semester since 1997. For the first time, the questionnaire was distributed to students at the Dhaka (Bangladesh) campus, again during the last class. The rest of this paper contrasts the results of this survey with the Melbourne results from 1997-2000. The questionnaire asked the students a number of questions including:

- The professional discipline area of their first degree.

- Their own perception of their knowledge of IT before and after completing this subject.

- How and when they made use of computers, and what applications they used.

- The relevance and interest to them of the particular topics covered in the course.

- The allocation of class time to various activities including systems development theory, business and management theory, and hands-on practical work.

This paper reports on the 228 survey responses in Melbourne (1997-2000) and the 27 survey responses from Dhaka (which represented $82 \%$ of the entire MIS Bangladesh class in that semester) gathered in semester two, 2001. The response rate for complete, usable surveys in Melbourne has generally been around $60 \%$ for the period 1997-2000. Table 2 below shows the number of complete responses during this pe- 
riod. (The numbers for 2000 include semester one and a single group of the subject that was offered in the December 1999 to February 2000 summer semester.)

\begin{tabular}{|c|c|}
\hline Year & $\begin{array}{c}\text { Number of Re- } \\
\text { sponses }\end{array}$ \\
\hline 1997 & 28 \\
\hline 1998 & 84 \\
\hline 1999 & 70 \\
\hline 2000 & 46 \\
\hline Melbourne Total & $\mathbf{2 2 8}$ \\
\hline Dhaka 2001 & $\mathbf{2 7}$ \\
\hline
\end{tabular}

Table 1: Response to the survey

\section{Student Profile}

Australian MBA programs typically insist that students must have at least some experience in business, and preferably in business management; these courses do not normally accept students who have just completed a bachelors degree (Sauer, Sharma et al. 1996a). The entry requirement for the MBA at Victoria University is an undergraduate degree and at least two years of some kind of work experience.

Given that the students had different professional backgrounds when they entered the course, one survey question asked what they had studied in their first degree. The survey showed that, over the years, approximately two-thirds of the students have entered the MBA program with a first degree in some type of business program (such as commerce, accounting or marketing). The remainder were classified as having a background in either science, engineering or computing (- most often computer science or computer engineering). The following graph represents the discipline fields studied by survey respondents before they entered the MBA program. It shows that the background of students in Dhaka was not much different from that in Melbourne, being mainly business students and sprinkling of students from other discipline areas. From the MIS viewpoint, this can make for some interesting challenges, as the students from different discipline areas expect different things from their only 'technology-based' core subject.

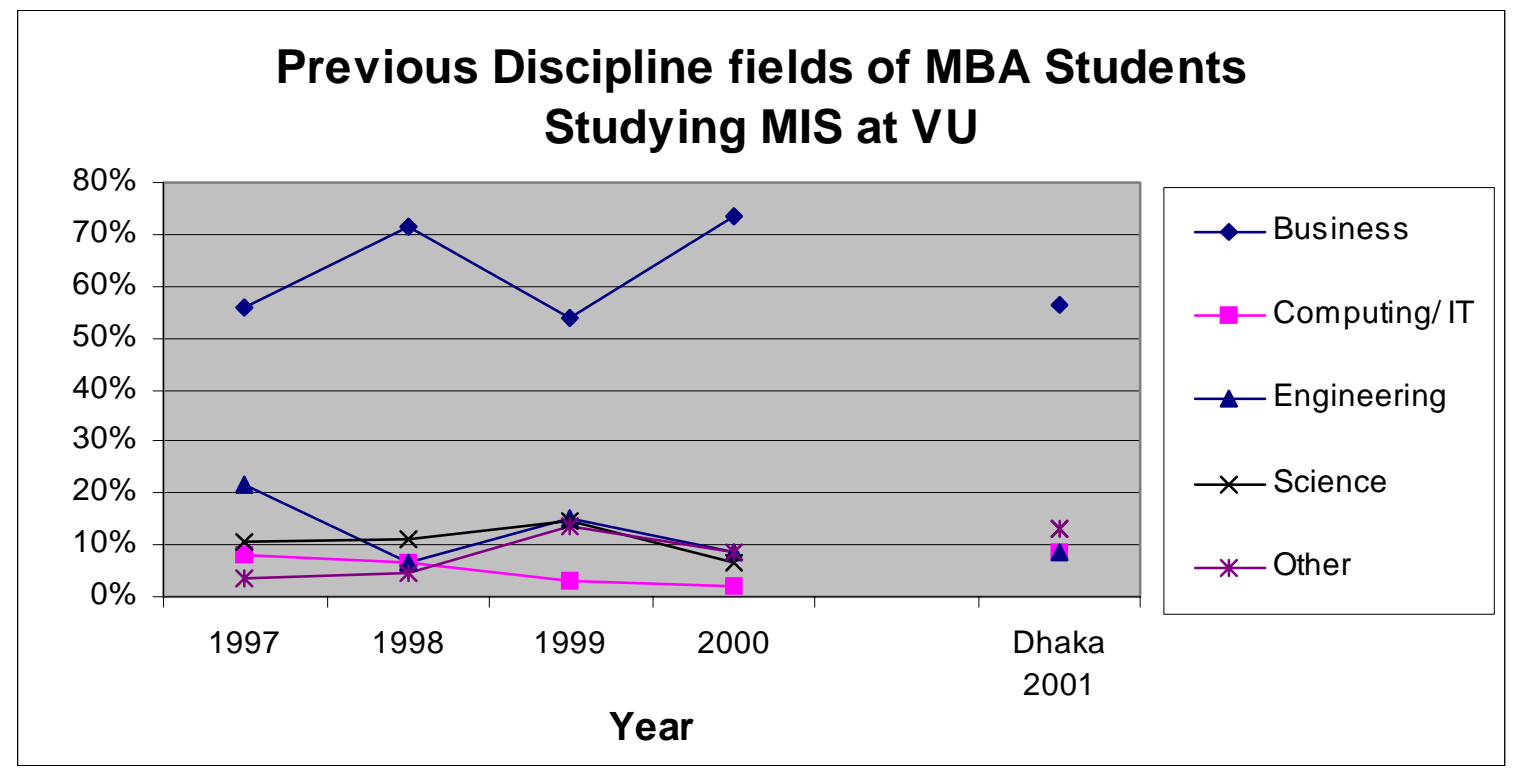

Figure 1: Previous Discipline Fields of MBA students studying MIS 
The authors wondered what the students' own perceptions were of their overall knowledge of IT and computing when they entered the course, and how this changed when they completed the MIS subject. The question used to determine this defined 'knowledge of IT and computing' quite broadly, as anything relating to the use of computers in business. This meant that it included both concepts and uses of computers in business, and also practical PC skills. The authors were also interested in how this differed between students with different types of professional backgrounds. The following tables represent the MBA students' own opinions of their knowledge of IT before and after they had completed the MIS subject. These answers were given in a five-point Likert scale ranging from $1=$ High through $3=$ Average to $5=$ None.

\begin{tabular}{|c|c|c|}
\hline Year & $\begin{array}{c}\text { Pre MBA } \\
\text { knowledge }\end{array}$ & $\begin{array}{c}\text { Post MIS } \\
\text { knowledge }\end{array}$ \\
\hline 1997 & 3.21 & 1.89 \\
\hline 1998 & 3.54 & 2.31 \\
\hline 1999 & 3.25 & 2.08 \\
\hline 2000 & 3.11 & 2.00 \\
\hline Melbourne Overall & $\mathbf{3 . 3 2}$ & $\mathbf{2 . 1 2}$ \\
\hline Dhaka 2001 & $\mathbf{3 . 3 3}$ & $\mathbf{2 . 5 2}$ \\
\hline
\end{tabular}

Table 2: Prior knowledge of IT, by year.

Table 2 shows that there was very little variation in the response to this question over the duration of the study. The authors were surprised to find that there was so little difference in the students' perceptions of their prior knowledge of IT due to their background. As one would expect, computing/IT students had a somewhat higher estimation of their own IT knowledge before the course, but other than that there were no major differences. It was reassuring to see that all students consistently thought they had gained a good deal of IT knowledge during the course, and interesting to note that the computing/IT students also saw their own knowledge as increasing. Interestingly, whilst students in Dhaka indicated a similar 'pre-MIS' level of knowledge on average as the Melbourne students, they indicated a lesser level of 'post-MIS' knowledge than any of the years of the Melbourne study. This is a finding that will be investigated further by the authors.

\section{Relevance and Interest of Topic Areas}

Using the five-point Likert scale, students were asked to rank the relevance and interest to themselves of each of the topic areas taught in the subject. They were also asked to indicate other topics they thought should have been covered in the subject. The results are shown in table 3 below. As with all university subjects, topic coverage varies slightly over the years, and a blank entry indicates that this topic was not taught during that year. Note also that a new topic, Use of the Internet for Business Research, was introduced for the first time in the MBA in Dhaka. 


\begin{tabular}{|l|c|c|c|c|c|c|}
\hline & $\mathbf{1 9 9 7}$ & $\mathbf{1 9 9 8}$ & $\mathbf{1 9 9 9}$ & $\mathbf{2 0 0 0}$ & $\begin{array}{c}\text { Melbourne } \\
\text { Average }\end{array}$ & $\begin{array}{c}\text { Dhaka } \\
\mathbf{2 0 0 1}\end{array}$ \\
\hline Eear & & 1.83 & 1.99 & 1.47 & $\mathbf{1 . 7 9}$ & $\mathbf{1 . 6 2}$ \\
\hline Strategic Use of IT & 1.54 & 1.92 & 2.01 & 1.58 & $\mathbf{1 . 8 3}$ & $\mathbf{1 . 8 1}$ \\
\hline Management of IT & 1.71 & 2.17 & 1.85 & 1.77 & $\mathbf{1 . 9 3}$ & $\mathbf{1 . 7 6}$ \\
\hline Innovation \& Change Mgt & & & 2.04 & 1.79 & $\mathbf{1 . 9 4}$ & \\
\hline Data Communications & & 2.07 & 1.99 & 1.82 & $\mathbf{1 . 9 8}$ & $\mathbf{1 . 7 9}$ \\
\hline Project Management & 1.82 & 2.15 & 1.91 & 2.10 & $\mathbf{2 . 0 3}$ & \\
\hline Small Business \& IT & 1.86 & 2.14 & & 2.00 & $\mathbf{2 . 0 7}$ & $\mathbf{1 . 9 6}$ \\
\hline Data modelling & 1.89 & 2.15 & 2.20 & 2.04 & $\mathbf{2 . 1 1}$ & $\mathbf{2 . 1 5}$ \\
\hline Process Modelling & 2.21 & 2.44 & 2.40 & 2.12 & $\mathbf{2 . 3 3}$ & $\mathbf{2 . 4 2}$ \\
\hline Visual Basic and databases & & 2.39 & 2.53 & 2.33 & $\mathbf{2 . 4 3}$ & \\
\hline Use of the Internet for Business Research & & & & & & $\mathbf{2 . 0 4}$ \\
\hline Overall & $\mathbf{1 . 8 9}$ & $\mathbf{2 . 1 4}$ & $\mathbf{2 . 1 0}$ & $\mathbf{1 . 8 9}$ & $\mathbf{2 . 0 5}$ & $\mathbf{1 . 9 4}$ \\
\hline
\end{tabular}

Table 3: Relevance and interest of topic areas, by year.

It is clear from these figures that each of the topic areas covered was considered both relevant and interesting by the majority of students, and there was very little variation over the years surveyed. What small amounts of variation there are could possibly be explained both by changes in the current interests of those lecturing in the subject and also by variations in students' interests. It was interesting to note that very few other topics were suggested by the students for inclusion in the subject, and no one extra topic was suggested by more than a couple of students. Although little variation can be seen between topics, there appears to be a slight preference for management/business related topics, and this is hardly surprising. The results from Dhaka match up reasonably well with the Melbourne results.

\section{Structure of the Subject}

Another question of interest was how students reacted to the structure of the MIS subject. Broadly speaking the subject can be divided into three structural parts:

- Hands-on practical work and assignments using PC applications such as Excel, Access, Visual Basic, PowerPoint and Microsoft Project.

- Information systems developments concepts and skills.

- Business management issues relating to information technology.

When the MBA course first began in Melbourne, the MIS subject was arranged to give these three parts about equal amounts of class time, and over the years this balance has varied somewhat. It is interesting to note, however, that the student's preference for how the course should be structured has been remarkably constant over this period, and that there has been little difference attributable to professional background. Taking the students wishes into account, in 2000 the course structure now reflects the breakdown shown. Again, it is interesting to note that the responses from Dhaka matched up reasonably closely with the Melbourne results. 


\begin{tabular}{|l||c|c|c|c|}
\hline \multicolumn{1}{|c|}{ Year } & Hands-on PC Apps & IS Concepts & Business/ Mgt Issues & Other \\
\hline 1997 & $37 \%$ & $32 \%$ & $30 \%$ & $1 \%$ \\
\hline 1998 & $41 \%$ & $29 \%$ & $28 \%$ & $2 \%$ \\
\hline 1999 & $39 \%$ & $29 \%$ & $30 \%$ & $2 \%$ \\
\hline 2000 & $38 \%$ & $30 \%$ & $31 \%$ & $1 \%$ \\
\hline Overall & $\mathbf{4 0} \%$ & $\mathbf{2 9} \%$ & $\mathbf{2 9} \%$ & $\mathbf{2} \%$ \\
\hline \hline Dhaka 2001 & $\mathbf{4 0 \%}$ & $\mathbf{2 4} \%$ & $\mathbf{3 2} \%$ & $\mathbf{4} \%$ \\
\hline
\end{tabular}

Table 4: Preference for subject structure, by year.

\section{Application Usage}

The authors were interested in the types of application packages that had been used by students over the years, and the proportions in which they used them. In Table 5, the results for Melbourne 1997 have been left out, as many of the applications packages were not listed as they were for subsequent years. It is important to interpret these results carefully. The results for word processing do not indicate that this application was used any less in 2000 than in 1998, it just means that it represented less of the overall usage of applications for that year. Also, for the first time there are some differences in the responses of Melbourne (2000) and Dhaka students. Note the low levels of Internet and e-mail usage in Dhaka compared to Melbourne. This could reflect the stage of diffusion of Internet technologies in Dhaka, or at the least their levels of acceptance amongst management students.

\begin{tabular}{|l|c|c|c|c|}
\hline Application & $\begin{array}{c}\text { Melb } \\
\mathbf{1 9 9 8} \\
(\%)\end{array}$ & $\begin{array}{c}\text { Melb } \\
\mathbf{1 9 9 9} \\
(\%)\end{array}$ & $\begin{array}{c}\text { Melb } \\
\mathbf{2 0 0 0} \\
(\%)\end{array}$ & $\begin{array}{c}\text { Dhaka } \\
\mathbf{2 0 0 1} \\
(\%)\end{array}$ \\
\hline Word Processing & 34 & 34 & 25 & $\mathbf{3 0}$ \\
\hline Spreadsheet & 15 & 15 & 13 & $\mathbf{2 1}$ \\
\hline Database & 10 & 13 & 11 & $\mathbf{1 0}$ \\
\hline Presentation & 13 & 12 & 10 & $\mathbf{8}$ \\
\hline Statistics & 4 & 4 & 5 & $\mathbf{2}$ \\
\hline Internet & 22 & 21 & 25 & $\mathbf{1 0}$ \\
\hline Electronic Mail & 16 & 16 & 16 & $\mathbf{7}$ \\
\hline Project Management & 5 & 3 & 3 & $\mathbf{3}$ \\
\hline Banking & 2 & 1 & 4 & $\mathbf{3}$ \\
\hline Games & 2 & 2 & 2 & $\mathbf{2}$ \\
\hline Other & 1 & 1 & 1 & $\mathbf{3}$ \\
\hline
\end{tabular}

Table 5: Software applications used, by year. 


\section{Conclusion}

So what does this all mean in relation to MIS subject development and delivery? The authors of this paper expected a greater variance in the attitudes of students from Bangladesh than to Melbourne, but it appears that, for the most part, the attitudes towards topics covered in MIS are quite similar in both cities. Also, and even more surprisingly, attitudes towards the amount of time devoted to 'hands-on' activities in class and the coverage of other topics were also very similar. This has occurred even after one takes into account the differences in relation to the diffusion of information technology, the different economies and the variations in delivery modes of the subject. It appears at the moment that the subject developers can adopt a 'steady as she goes' attitude; at least in relation to the topics being covered and the balance of time spent covering them.

\section{References}

Burgess, S. and Tatnall, A. (1997). 'Information Technology for Managers: Australian Generic MBA Programs'. The Place of Information Technology in Management and Business Education. Barta, B. Z., Tatnall, A. and Juliff, P. (Eds). IFIP / Chapman \& Hall, London: 35-42.

Burgess, S. and Tatnall, A. (2000). 'Student views on the curriculum content of Victoria University's MBA subject in Management Information Systems'. Victoria University Department of Information Systems Working Paper.

Burke, K. (1993). 'MBA Investment Reaps Big Rewards in the Marketplace'. The Australian Financial Review: Management Education Survey.

Cameron, Nadia, 2001, ‘Australian Education on Top’, Business Asia, Vol.9, Iss.7, August: 20-22.

Clout, J. and Marshall, K. (1995). MBAs in Australia: A Guide to Graduate Management Education. Financial Review Library, Melbourne.

De Boer, S.J and Walbeek, M.M., 1999, 'Information Technology in Developing Countries: A Study to Guide Policy Formation', International Journal of Information Management, June: 207.

Dwyer, M. and Marshall, K. (1993). Guide to MBA Programs in Australia. Australian Financial Review Library, Melbourne.

La Plante, A. (1991). 'Making the Grade'. Infoworld 13(6): 50-52.

Persaud, Avinash, 2001, 'The Knowledge Gap. (Equity Stakes Sold to Raise Capital to Realise Good Ideas), Foreign Affairs, Vol.80, No.2, March-April: 107

Sauer, C., Sharma, R. and Potter, B. (1996a). 'Are General Managers Well Prepared to Manage Information Technology? The Role of IT in General MBA Programmes in Australia'. Australian Graduate School of Management, Working Paper( 96040).

Sauer, C., Sharma, R. and Potter, B. (1996b). 'IT in General MBA Programmes in Australia: Summary Results from a Survey'. Australian Graduate School of Management, Working Paper ( 96-041).

Silver, M. S., Markus, M. L. and Beath, C. M. (1995). 'The Information Technology Interaction Model: A Foundation for the MBA Core Course'. MIS Quarterly (September): 361-390.

Tatnall, A. and Davey, B. (2000). 'Information Systems Development for Australian Post-Graduate Management Students'. IFIP World Computer Congress (ITBM2000), IFIP/Kluwer, Beijing, China.

Tatnall, A., Davey, B., Burgess, S., et al. (2000). Management Information Systems - concepts, issues, tools and applications. ( $2^{\text {nd }}$ edition). Data Publishing, Melbourne.

The Economist, 2001, 'Fishermen on the Net: The Digital Revolution is Helping the Poor, Too', Nov.10.

The Economist, 2000, 'Falling through the Net? Information Technology in Developing Countries', Vol. 356, Sept 23. 


\section{Biographies}

Stephen Burgess is a senior lecturer in the School of Information Systems at Victoria University, Melbourne, Australia. He has a bachelors degree in Accounting and a Graduate Diploma in Commercial Data Processing, both from Victoria University, Australia; a Master of Business (Information Technology) from RMIT, Australia and a PhD from Monash University, Australia in the area of small business to consumer interactions on the internet. His research and teaching interests include the use of IT in small business, the strategic use of IT, B-C electronic commerce and IT management education.

Golam M Chowdhury is the MBA Course Director, Bangladesh for the Dhaka campus of Victoria University, Melbourne, Australia. Earlier, he has been teaching at the Institute of Business Administration, University of Dhaka as an Associate Professor. Mr. Chowdhury has obtained his MBA from Aston Business School, Aston University, Birmingham, U.K. He also has a Diploma in Management Studies (DMS) from Kingston Business School, Kingston University and a B.Sc. (Hons.) from North London University, U.K. His teaching, consulting and research interests include global collaboration in business education and institutional development.

Arthur Tatnall is a Senior Lecturer in the School of Information Systems at Victoria University in Melbourne, Australia. He holds bachelors degrees in science and education and a research master of arts in which he explored the origins of business computing education in Australian universities. His $\mathrm{PhD}$ involved a study in curriculum innovation in which he investigated the manner in which Visual Basic entered the curriculum of an Australian university. His research interests include technological innovation, information systems curriculum, Visual Basic programming, project management, electronic commerce, and information technology in educational management. 